\title{
HUBUNGAN ANTARA GAYA KEPEMIMPINAN PATH GOAL SUPERVISOR PABRIK BAJA DENGAN TINGKAT KEPATUHAN SOP (STANDARD OPERATIONAL PROCEDURE) PEKERJA
}

\author{
Wahyu Fahrul Ridho \\ Persatuan Alumni Kesehatan Masyarakat Indonesia (PERSAKMI) Provinsi Jawa Timur \\ E-mail: wahyu.riedho@gmail.com
}

\begin{abstract}
Employee ignorance on Standard Operational Procedures (SOP) is one of the main causes of workplace accidents. This study was conducted to analyze the correlation between path goal leadership implemented by Gresik steel factory supervisors and employee obedience on company SOP. This study applied quantitative approach and cross-sectional research design. The data were collected through observation and interview on 52 respondents consisting of employees working led by 4 different supervisors. Systematic random sampling is used for sampling method. In-depth interviews were conducted to gain more information regarding the variables analyzed in this study. The independent variables analyzed in this study were path goal leadership style implemented by the supervisors and the dependent one is SOP obedience. This study found that employee obedience level on company SOP of each working units is $86 \%$ for drilling unit; $78.57 \%$ for marking and cutting unit; 100\% for assembly unit; and $41.67 \%$ on painting unit. The results of Spearman correlation test indicated that path goal leadership style implemented by the supervisors significantly correlated with obedience level of the employees on company SOP with $p<0.05$. there were positive correlation among the variables with correlation coefficient $0.416(p=0.001)$. Based on these findings, it could be concluded that the better path goal leadership style implementation made by the supervisors the higher employee obedience level on company SOP.
\end{abstract}

Keywords: leadership style, Path Goal Theory, SOP obedience, occupational safety

\begin{abstract}
ABSTRAK
Ketidakpatuhan pekerja terhadap Standard Operation Procedure (SOP) merupakan salah satu penyebab kecelakaan kerja. Penelitian dilakukan untuk mengetahui hubungan antara gaya kepemimpinan path goal supervisor pabrik baja Gresik dengan tingkat kepatuhan pekerja terhadap SOP perusahaan. Penelitian dilaksanakan dengan rancangan cross sectional dengan menggunakan pendekatan kuantitatif. Observasi dan wawancara dilaksanakan pada 52 responden pekerja workshop bagian fabrikasi di 4 unit yang dipimpin 4 supervisor. Pengambilan sampel dengan cara systematic random sampling. Variabel bebas penelitian adalah gaya kepemimpinan path goal supervisor dan variabel terikatnya adalah Kepatuhan SOP. Tingkat Kepatuhan SOP dalam penelitian ini untuk supervisor unit drilling sebanyak $86 \%$ pekerja, supervisor unit markingcutting sebanyak 78,57\% pekerja, supervisor unit assembly $100 \%$ pekerja, dan supervisor unit painting $41,67 \%$ pekerja. Pengujian dengan uji korelasi Spearman menunjukkan gaya kepemimpinan path goal supervisor mempunyai hubungan yang bermakna dengan tingkat kepatuhan SOP pekerja masing-masing supervisor $(p<0,05)$. Hubungan antar variabel memiliki arah positif dengan koefisien korelasi sebesar $0,416(\mathrm{p}=0,001)$. Kesimpulannya ialah supervisor unit yang menerapkan gaya kepemimpinan path goal yang lebih baik memiliki tingkat rata-rata kepatuhan pekerja yang lebih baik daripada supervisor yang menerapkan gaya kepemimpinan path goal yang kurang. Penerapan gaya kepemimpinan path goal dari supervisor perlu dipertimbangkan oleh perusahaan agar pekerja patuh terhadap SOP yang ada di perusahaan
\end{abstract}

Kata kunci: gaya kepemimpinan, Path Goal Theory, kepatuhan SOP, keselamatan kerja

\section{PENDAHULUAN}

Hazard di tempat kerja selalu ada walaupun pengendalian sudah sebaik mungkin dilakukan, karena pada prinsipnya bahaya selalu ada dimanamana. Bahaya tersebut dapat menyebabkan kecelakaan kerja jika tidak dilakukan pengendalian. Penyebab kecelakaan kerja menurut teori domino yang dikeluarkan oleh Heinrich, kecelakaan disebabkan oleh sebab yang saling berurutan mulai dari keturunan atau lingkungan sosial, kesalahan seseorang, unsafe act dan unsafe condition, kecelakaan dan kemudian cidera (Notoatmodjo, 2007).

Berdasarkan data yang dirilis oleh Health and Safety Executive United Kingdom (HSE, 2014) pada tahun 2014, di UK terjadi 133 kecelakaan kerja fatal yang menyebabkan kematian dan 77.593 korban kecelakaan non fatal. Sekitar total 2,7 juta hari kerja 
hilang disebabkan kecelakaan kerja (HSE, 2014). Di Indonesia sendiri kecelakaan kerja pada tahun 2014 triwulan ke 2 tercatat total ada 18.105 kasus. 18.105 kasus kecelakaan kerja tersebut 10.101 diantaranya sembuh, 7.335 sembuh tapi belum bisa bekerja, 343 cacat tetap dan 101 diantaranya meninggal dunia. Kerugian yang dialami mencapai kurang lebih 2 miliar rupiah dan hari kerja yang hilang hampir mencapai 5 juta hari kerja (Depnakertrans, 2014). Kejadian kecelakaan kerja yang terjadi menurut Menteri Tenaga Kerja dan Transmigrasi, Kecelakaan kerja sebagian besar disebabkan oleh rendahnya kedisiplinan dan tingkat kesadaran tenaga kerja.

Menurut teori domino dari Heinrich, adanya suatu kecelakaan kerja ialah berasal dari kurangnya pengendalian dari pihak manajemen. Banyak perusahaan yang menyadari hal tersebut dan berusaha menerapkan cara-cara kerja yang aman agar pekerja terhindar dari kecelakaan kerja dan perusahaan terhindar dari kerugian, salah satu upaya yang dilakukan adalah perumusan suatu tata cara kerja yang standard yang telah dirumuskan dengan matang. Tata cara tersebut dibakukan dan disebut dengan istilah Standard Operating Procedure (SOP).

Kemampuan seseorang memimpin memiliki hubungan dengan perilaku bawahannya. Penelitian yang dilakukan oleh Pudjiono (2003) bahwa gaya kepemimpinan memiliki pengaruh positif terhadap kepuasan kerja, motivasi dan kinerja karyawan. Penelitian yang dilakukan oleh Zaini (2013) juga meneliti bahwa gaya seseorang memimpin memiliki outcome yang berbeda beda dalam performa kerja, psikologis dan kepatuhan di tempat kerja. Supervisor bertindak dan berperilaku akan mempengaruhi pekerjanya bereaksi. Selain kepada performa kerja, gaya kepemimpinan juga diduga memiliki hubungan dengan sebab tidak langsung performa yaitu kondisi mental atau psikologis seseorang seperti stress. Penelitian yang dilakukan oleh Dyan (2013) membuktikan bahwa gaya seorang supervisor memimpin memiliki hubungan yang signifikan terhadap tingkat stress pekerja.

Pabrik Baja Gresik adalah perusahaan kontraktor baja dengan fasilitas fabrikasi terbesar di Indonesia Timur yang sudah berdiri sejak tahun 1985. Jenis pekerjaan yang sama dengan jumlah yang berbeda, perbedaan kemampuan bekerja dan pemberian target yang berbeda-beda dari supervisor di Pabrik Baja Gresik. Tiap supervisor memiliki gaya dan performa yang berbeda beda dalam memimpin. Adanya perbedaan dalam gaya memimpin sesuai untuk mempelajari apakah kepatuhan terhadap SOP oleh pekerja memiliki suatu hubungan dengan perbedaan gaya memimpin supervisor pekerja.

Perbedaan dalam gaya memimpin, akan dapat dilihat bahwa tiap pekerja akan memiliki suatu sikap yang berbeda-beda terhadap supervisor sehingga sesuai untuk dipelajari bagaimana hubungannya dalam performa bekerja. Variasi didalam ke pemimpinan supervisor diduga dapat menyebabkan variasi pula dalam perilaku pekerja dalam mematuhi SOP yang telah diberikan Pabrik Baja Gresik Gresik. Kepatuhan merupakan suatu perilaku yang dipengaruhi oleh banyak hal salah satunya adalah sikap pimpinan.

Path Goal Theory adalah teori atau tentang kepemimpinan yang dicetuskan oleh Martin Evans pada tahun 1970 yang kemudian dikembangkan oleh Robert House pada tahun 1970 dan kemudian mengalami revisi pada tahun 1996. Path Goal berdasarkan expectancy theory dari Vroom yaitu seorang individu akan berperilaku sesuai dengan pengharapan akan outcome dari suatu tujuan dan seberapa menarik outcome tersebut bagi individu (Northhouse, 2013). Path Goal Theory paling tepat dideskripsikan sebagai suatu proses pemimpin memilih suatu gaya kepemimpinan tertentu berdasarkan kebutuhan pekerja dan lingkungan kerja, sehingga pemimpin dapat membawa pekerja menuju tujuan yang diharapkan (Northhouse, 2013).

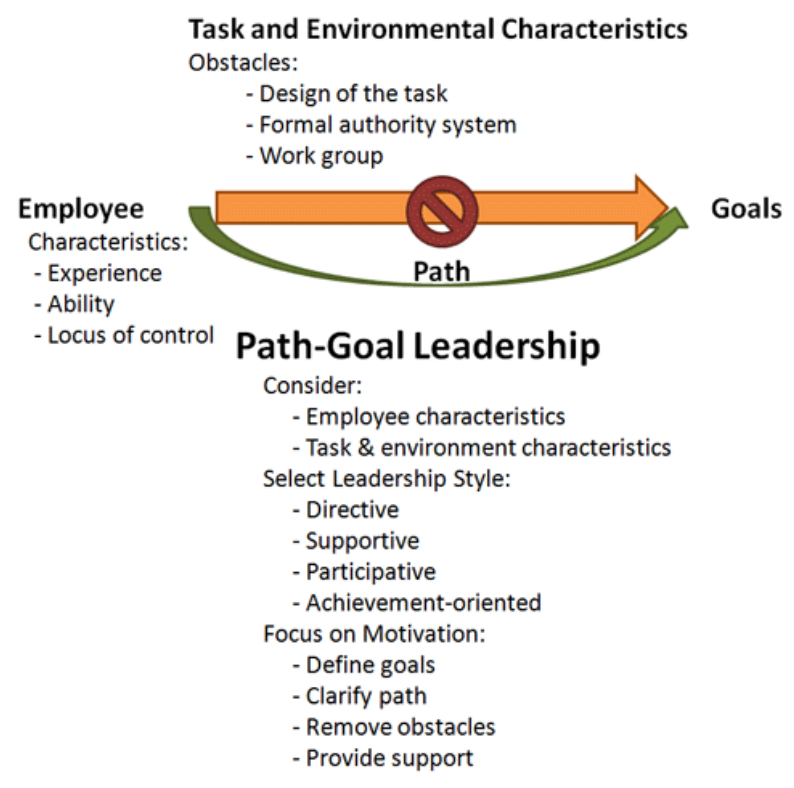

Gambar 1. Path Goal Leadership Theory

House (1996), mendefinisikan Path Goal Theory memiliki 4 aspek yaitu directive, supportive, 
participative, dan achievement oriented. Directive memiliki karakteristik pemimpin menginformasikan pengikutnya pada apa yang diharapkan dari pekerja, seperti mengatakan apa yang harus dilakukan, bagaimana melakukan tugas, dan menentukan penjadwalan dan koordinasi kerja. Hal ini paling efektif ketika orang tidak yakin tentang tugas atau ketika ada banyak ketidakpastian dalam lingkungan kerja. Supportive memiliki karakteristik pemimpin membuat pekerjaan menyenangkan bagi para pekerja dengan menunjukkan kepedulian pada pekerja dan berperilaku ramah dan mudah didekati. Hal ini paling efektif dalam situasi di mana tugas dan hubungan sosial menantang secara fisik atau psikologis. Participative memiliki karakteristik pemimpin berkonsultasi dengan para pekerja sebelum membuat keputusan tentang bagaimana untuk melanjutkan pekerjaan.

Hal ini paling efektif diterapkan bila bawahan sangat terlatih dan terlibat dalam pekerjaan mereka. Achievement oriented memiliki karakteristik pemimpin menetapkan tujuan yang menantang untuk pengikutnya, mengharapkan mereka untuk bekerja di keadaan paling optimal, dan menunjukkan kepercayaan diri dalam kemampuan mereka untuk memenuhi harapan. Hal ini paling efektif dalam lingkungan kerja profesional, seperti teknis, ilmiah; atau lingkungan prestasi, seperti penjualan. Pada dasarnya Path Goal Theory berasumsi bahwa pemimpin dapat merubah gaya kepemimpinannya sesuai dengan situasi yang dibutuhkan. Pemimpin diasumsikan fleksibel dalam pengambilan keputusan gaya kepemimpinan. Hal ini sejalan dengan penelitian yang menyebutkan bahwa genetik adalah pemandu perilaku secara internal, sementara pengalaman ialah yang mendefinisikan hasil akhir dari terjadi atau tidak terjadinya suatu perilaku (Ridley, 2003).

\section{METODE}

Berdasarkan cara pengumpulan datanya, penelitian ini merupakan penelitian observasional, karena data diperoleh melalui pengamatan dan wawancara. Selain itu, objek penelitian tidak diberi perlakuan selama penelitian berlangsung. Berdasarkan dari sifat masalah dan analisa datanya, maka penelitian ini termasuk penelitian analitik, yaitu penelitian dilakukan dengan tujuan untuk membuat gambaran tentang suatu Variabel yang dipelajari dalam penelitian ini antara lain adalah usia, masa kerja, tingkat pendidikan, gaya kepemimpinan supervisor dan tingkat kepatuhan SOP pekerja bagian fabrikasi.

Pengkategorian variabel usia dan masa kerja menggunakan median. Yaitu mengelompokkan umur sesuai umur median kelompok sampel dan mengelompokkan masa kerja kelompok sampel berdasarkan median masa kerja kelompok sampel. Dari hasil perhitungan median, ditentukan usia menjadi 2 kategori yaitu muda ( $\leq 28$ tahun) dan tua ( $>28$ Tahun). Sementara masa kerja menjadi belum lama ( $\leq 5$ tahun) dan lama $(>5$ tahun). Pengkategorian tingkat pendidikan ialah menggunakan tamat SMA dan SMA yang bertujuan memudahkan pengkategorian.

Tingkat kepatuhan SOP dikategorikan berdasarkan skor tingkat kepatuhan yang dikategorikan menjadi 2 kelompok yaitu patuh dan kurang patuh. Pengkategorian gaya kepemimpinan adalah berdasarkan tingkat penguasaan gaya kepemimpinan path goal theory yang diterapkan supervisor dan dinilai oleh pekerja masing-masing. Supervisor yang dinilai dapat menerapkan keempat gaya pemimpin sesuai lingkungan kerja dan kondisi yang tepat, dikategorikan memiliki gaya kepemimpinan path goal sangat baik. Supervisor yang dinilai dapat menerapkan hanya dua dari empat gaya kepemimpinan path goal dikategorikan memiliki gaya kepemimpinan path goal kurang. Supervisor yang dinilai dapat menerapkan dua atau kurang gaya kepemimpinan path goal dan belum sesuai kondisi dan lingkungan kerja dikategorikan memiliki gaya kepemimpinan path goal sangat kurang.

Data yang dikumpulkan dalam penelitian ini adalah data primer dan data sekunder. Data primer didapatkan dengan cara observasi untuk mengetahui adalah usia, masa kerja, tingkat pendidikan, gaya kepemimpinan supervisor dan tingkat kepatuhan SOP pekerja bagian fabrikasi Sebelum penerjunan kelapangan dilakukan uji validitas dan reliabilitas terhadap instrument yang akan digunakan pada saat penelitian

Teknik analisis data akan dilakukan setelah proses editing, coding, dan entry data. Dalam proses tersebut juga akan dilakukan cleaning data. Kemudian dilakukan analisa statistik menggunakan uji korelasi spearman Hal ini disebabkan skala data adalah ordinal untuk variable independen, dan skala data adalah nominal hubungan antar variabel. Ditinjau dari segi waktu, rancangan penelitian ini termasuk dalam penelitian cross sectional karena 
wawancara dan pengamatan terhadap variabel dilakukan serentak dalam periode waktu tertentu.

Objek dari penelitian unit masing-masing pekerja yang dibawahi oleh 4 supervisor. 4 unit tersebut ialah marking cutting, drilling, assembly dan painting. Penelitian dilakukan di area workshop bagian fabrikasi Pabrik Baja Gresik. Penelitian dilakukan di bulan Juli 2015.

\section{HASIL}

\section{Karakteristik Individu}

Berdasarkan usia responden, Supervisor Unit Drilling membawahi 9 orang responden atau sekitar $60 \%$ responden yang tergolong berusia relatif muda, dan 6 orang responden atau sekitar $57,14 \%$ responden yang tergolong berusia relatif tua. Supervisor Unit Marking-Cutting membawahi 8 orang responden atau sekitar $57,14 \%$ responden yang tergolong berusia relatif muda, dan 6 orang responden atau sekitar $42,85 \%$ responden yang tergolong berusia relatif tua. Supervisor Unit Assembly membawahi 8 orang responden atau $53,33 \%$ responden yang tergolong berusia relatif muda dan 7 orang responden atau sekitar 46,67\% responden yang tergolong berusia relatif tua. Sedangkan Supervisor Unit Painting membawahi sekitar 7 orang responden atau sekitar 58,33\% responden yang tergolong berusia relatif muda dan sisanya tergolong berusia relatif tua.

Berdasarkan tingkat pendidikan responden, Supervisor Unit Drilling membawahi 2 orang responden atau sekitar 13,33\% responden yang tergolong belum tamat pendidikan SMA, dan 13 orang responden atau sekitar $86,67 \%$ responden yang tergolong telah tamat pendidikan SMA. Supervisor Unit Marking-Cutting membawahi 3 orang responden atau sekitar $21,43 \%$ responden yang tergolong belum tamat pendidikan SMA, dan 11 orang responden atau sekitar $78,57 \%$ responden yang tergolong telah tamat pendidikan SMA. Supervisor Unit Assembly membawahi 4 orang responden atau $26,67 \%$ responden yang tergolong belum tamat pendidikan SMA dan 11 orang responden atau sekitar $73,33 \%$ responden yang tergolong telah tamat pendidikan SMA. Sedangkan Supervisor Unit Painting membawahi sekitar 3 orang responden atau sekitar $25 \%$ responden yang tergolong belum tamat pendidikan SMA, dan 9 orang responden atau sekitar $75 \%$ responden yang tergolong telah tamat pendidikan SMA.

Berdasarkan masa kerja responden, Supervisor Unit Drilling membawahi 8 orang responden atau sekitar 53,33\% responden yang tergolong belum lama atau bekerja kurang dari atau sama dengan 5 tahun, dan 7 orang responden atau sekitar $46,67 \%$ responden yang tergolong telah bekerja lebih dari 5 tahun. Supervisor Unit Marking-Cutting membawahi 9 orang responden atau sekitar $64,29 \%$ responden yang tergolong belum lama atau bekerja kurang dari atau sama dengan 5 tahun, dan 5 orang responden atau sekitar $35,71 \%$ responden yang tergolong telah bekerja lebih dari 5 tahun. Supervisor Unit Assembly membawahi 9 orang responden atau $60 \%$ responden yang tergolong belum lama atau bekerja kurang dari atau sama dengan 5 tahun, dan 6 orang responden atau sekitar $40 \%$ responden yang tergolong telah bekerja lebih dari 5 tahun. Sedangkan Supervisor Unit Painting membawahi sekitar 7 orang responden atau sekitar 58,33\% responden yang tergolong belum lama atau bekerja kurang dari atau sama dengan 5 tahun, dan 5 orang responden atau sekitar $41,67 \%$ responden yang tergolong telah bekerja lebih dari 5 tahun.

Tabel 1. Karakteritik Individu Responden

\begin{tabular}{|c|c|c|c|c|c|c|}
\hline \multirow{3}{*}{ Supervisor } & \multicolumn{2}{|c|}{$\begin{array}{c}\text { Jumlah Responden } \\
\text { Berdasarkan Usia }\end{array}$} & \multicolumn{2}{|c|}{$\begin{array}{c}\text { Tingkat Pendidikan } \\
\text { Responden }\end{array}$} & \multicolumn{2}{|c|}{ Lama Masa Kerja } \\
\hline & $\begin{array}{c}\text { Muda } \\
(\leq 28 \text { tahun })\end{array}$ & $\begin{array}{c}\text { Tua } \\
\text { (>28 Tahun) }\end{array}$ & $\begin{array}{c}\text { Tidak Tamat } \\
\text { SMA }\end{array}$ & Tamat SMA & $\begin{array}{c}\text { Belum Lama } \\
\text { ( } \leq 5 \text { tahun) }\end{array}$ & $\begin{array}{c}\text { Lama } \\
(>5 \text { Tahun })\end{array}$ \\
\hline & $\%$ & $\%$ & $\%$ & $\%$ & $\%$ & $\%$ \\
\hline Supervisor Unit Drilling & 60,00 & 40,00 & 13,33 & 86,67 & 53,33 & 46,67 \\
\hline Supervisor Unit $\mathrm{M}-\mathrm{C}$ & 57,14 & 42,85 & 21,43 & 78,57 & 64,29 & 35,71 \\
\hline Supervisor Unit Assembly & 53,33 & 46,67 & 26,67 & 73,33 & 60,00 & 40,00 \\
\hline Supervisor Unit Painting & 58,33 & 41,67 & 25,00 & 75,00 & 58,33 & 41,67 \\
\hline Total & 57,21 & 42,79 & 21,61 & 78,39 & 58,99 & 41,01 \\
\hline
\end{tabular}




\section{Tingkat Kepatuhan}

Berdasarkan tingkat kepatuhan SOP responden, Supervisor Unit Drilling membawahi 2 orang responden atau sekitar 13,33\% responden yang tergolong kurang patuh terhadap SOP PT. BSB, dan 13 orang responden atau sekitar $86,67 \%$ responden yang tergolong telah patuh terhadap SOP PT. BSB. Supervisor Unit Marking-Cutting membawahi 3 orang responden atau sekitar $21,43 \%$ responden yang tergolong kurang patuh terhadap SOP PT. $\mathrm{BSB}$, dan 11 orang responden atau sekitar 78,57\% responden yang tergolong telah patuh terhadap SOP PT. BSB. Supervisor Unit Assembly membawahi 15 orang responden atau $100 \%$ responden di bawah Supervisor Unit Assembly tergolong telah patuh terhadap SOP PT. BSB. Sedangkan Supervisor Unit Painting membawahi sekitar 7 orang responden atau sekitar 58,33\% responden yang tergolong kurang patuh terhadap SOP PT. BSB, dan 5 orang responden atau sekitar $41,67 \%$ responden yang tergolong telah patuh terhadap SOP PT. BSB.

Tabel 2. Tingkat Kepatuhan Responden

\begin{tabular}{lrrrr}
\hline & \multicolumn{3}{c}{ Tingkat Kepatuhan } \\
& Penerapan SOP \\
\cline { 2 - 5 } \multicolumn{1}{c}{ Supervisor } & $\begin{array}{c}\text { Kurang } \\
\text { Patuh }\end{array}$ & Patuh \\
\cline { 2 - 5 } & $\Sigma$ & $\mathbf{\%}$ & $\sum$ & $\mathbf{\%}$ \\
\hline Supervisor Unit Drilling & 2 & 13,33 & 13 & $86,6,7$ \\
Supervisor Unit Marking- & 3 & 21,43 & 11 & 78,57 \\
Cutting & & & & \\
Supervisor Unit Assembly & 0 & 0 & 15 & 100 \\
Supervisor Unit Painting & 7 & 58,33 & 5 & 41,67 \\
\hline Total & $\mathbf{1 2}$ & $\mathbf{2 3 , 2 7}$ & $\mathbf{4 4}$ & $\mathbf{7 6 , 6 9}$ \\
\hline
\end{tabular}

\section{Gaya Kepemimpinan}

Berdasarkan pengukuran tingkat kepatuhan, sebagian besar responden dari pekerja Supervisor Unit Drilling atau sekitar 93,33\% responden menilai gaya kepemimpinan Supervisor Unit Drilling sangat baik. Maka berdasarkan hal tersebut didapat hasil gaya kepemimpinan Path Goal yang cenderung ditunjukkan oleh Supervisor Unit Drilling ialah Sangat Baik. Artinya Supervisor Unit Drilling mampu dengan sangat baik menerapkan keempat aspek gaya kepemimpinan path goal yaitu supportive, directive, participative dan achievement oriented. Supervisor Unit Drilling mampu menerapkan keempat gaya kepemimpinan tersebut sesuai dengan kondisi dan situasi pekerjaan yang tepat menurut pekerja.
Sebagian besar responden dari pekerja Supervisor Unit Marking Cutting atau sekitar 57,14\% responden menilai gaya kepemimpinan Supervisor Unit Marking Cutting baik. Maka berdasarkan hal tersebut didapat hasil gaya kepemimpinan Path Goal yang cenderung ditunjukkan oleh Supervisor Unit Marking Cutting ialah Baik. Artinya Supervisor Unit Marking Cutting mampu dengan baik menerapkan beberapa aspek gaya kepemimpinan path goal yaitu supportive, directive, participative dan achievement oriented. Supervisor mampu menerapkan beberapa namun tidak semua dari gaya kepemimpinan tersebut dan sesuai dengan kondisi dan situasi pekerjaan yang tepat menurut pekerja.

Seluruh responden dari pekerja Supervisor Unit Assembly atau sekitar $86,67 \%$ responden menilai gaya kepemimpinan Supervisor Unit Assembly sangat baik. Maka berdasarkan hal tersebut didapat hasil gaya kepemimpinan Path Goal yang cenderung ditunjukkan oleh Supervisor Unit Assembly ialah Sangat Baik. Artinya Supervisor Unit Assembly mampu dengan sangat baik menerapkan keempat aspek gaya kepemimpinan path goal yaitu supportive, directive, participative dan achievement oriented. Supervisor Unit Assembly mampu menerapkan keempat gaya kepemimpinan tersebut sesuai dengan kondisi dan situasi pekerjaan yang tepat menurut pekerja.

Sebagian besar responden dari pekerja Supervisor Unit Painting atau sekitar 58,33\% responden menilai gaya kepemimpinan Supervisor Unit Painting Kurang. Artinya Supervisor Unit Painting masih kurang mampu dalam menerapkan keempat aspek gaya kepemimpinan path goal yaitu supportive, directive, participative dan achievement oriented. Supervisor Unit Painting cenderung menunjukkan salah satu atau beberapa gaya saja dan kurang mampu menerapkannya di situasi dan kondisi pekerjaan yang tepat menurut responden.

\section{Hubungan Gaya Kepemimpinan dan Kepatuhan}

Supervisor yang memiliki jumlah responden pekerja yang kurang patuh terhadap SOP tertinggi yaitu sebanyak 7 responden atau sekitar 58,33\% total responden pekerja Supervisor Unit Painting yang menerapkan gaya kepemimpinan yang kurang. Sedangkan untuk responden yang patuh terhadap SOP yang tertinggi yaitu sebanyak 15 pekerja atau sekitar 100\% seluruh responden pekerja Supervisor Unit Assembly menganggap Supervisor Unit Assembly menerapkan gaya kepemimpinan yang sangat baik. 
Hasil uji korelasi spearman melalui software SPSS menunjukkan bahwa nilai signifikansi ialah $\mathrm{p}=0,001$ dengan $\alpha=0,05(\mathrm{p}<\alpha)$, dan koefien korelasi bernilai 0,441 . Maka dapat disimpulkan bahwa ada hubungan antara gaya kepemimpinan Path Goal Supervisor dengan tingkat kepatuhan penerapan SOP di Pabrik Baja Gresik maka Ho ditolak.

\section{PEMBAHASAN}

\section{Tingkat Kepatuhan SOP}

Sebagian besar responden pekerja fabrikasi unit drilling yang patuh terhadap SOP PT. Bangun Sarana Baja Gresik mengerti terhadap isi dan instruksi yang ada di SOP PT. Bangun Sarana Baja Gresik dan juga menganggap positif tentang SOP PT. Bangun Sarana Baja Gresik. Cara bekerja pekerja unit drilling juga sesuai dengan SOP yang ada dan memakai perlengkapan kerja yang diwajibkan. Pekerja responden unit drilling mendapat dukungan keluarga untuk bekerja yang terbaik dan memberikan hasil yang optimal dan mematuhi peraturan agar tidak mencelakakan diri sendiri. Pekerja unit drilling merasa terpengaruh atau terbawa terhadap rekanrekannya satu unit yang patuh terhadap peraturan. Pekerja unit drilling mengaku mereka mematuhi SOP yang ada karena rekan kerja mereka yang lain juga demikian. Mereka merasa pengaruh dari teman dan keluarga menjadi hal dominan dalam kepatuhan penerapan SOP yang ada di PT. Bangun Sarana Baja Gresik.

Milgram dalam Wade dan Travis (2007), menyebutkan bahwa subjek yang bekerja dengan teman dekat atau dalam peer group akan cenderung meniru apa yang dilakukan oleh rekan-rekannya baik itu sikap patuh atau tidak. Hal ini juga didukung oleh Eisenberger (2001), bahwa dukungan sosial dapat memperkuat komitmen secara afektif dan performa dalam proses timbal balik.

Sebagian besar responden fabrikasi unit marking-cutting yang patuh terhadap SOP PT. Bangun Sarana Baja Gresik mengerti terhadap isi dan instruksi yang ada di SOP PT. Bangun Sarana Baja Gresik dan juga tentang SOP PT. Bangun Sarana Baja Gresik. Responden yang patuh menganggap SOP adalah hal yang baik dalam melakukan pekerjaan dan mereka merasa tidak terganggu dengan adanya SOP yang diberlakukan perusahaan. SOP dan kebijakan perusahaan adalah hal yang positif bagi sebagian responden. Mereka percaya adanya SOP adalah salah satu hal yang melindungi mereka dari bahaya kerja yang akan timbul selain untuk menghasilkan pekerjaan dengan kualitas yang baik bagi perusahaan.

Dalam salah satu penelitian yang dilakukan oleh Natasia (2014), didapat hasil bahwa sikap atau persepsi terhadap SOP memiliki pengaruh yang signifikan terhadap kepatuhan seseorang terhadap prosedur yang ditetapkan. Dari penelitian tersebut didapat hasil pekerja yang memiliki persepsi yang baik terhadap SOP memiliki tingkat kepatuhan sebesar 1.984 kali lebih baik dibanding dengan yang memiliki persepsi yang buruk terhadap SOP. Hal ini juga diperkuat dengan model Theory of Planned Behaviour dari Ajzen dalam Feldman (2011), bahwa kepercayaan normatif dan kepercayaan subjektif yang positif terhadap perilaku atau peraturan yang mengikuti perilaku tersebut adalah salah satu elemen inti agar suatu perilaku dapat terjadi.

Sebagian besar responden fabrikasi unit assembly yang patuh terhadap SOP PT. Bangun Sarana Baja Gresik mengerti terhadap isi dan instruksi yang ada di SOP PT. Bangun Sarana Baja Gresik dan juga tentang SOP PT. Bangun Sarana Baja Gresik. Responden merasa mereka mendapat support yang baik dari sesama pekerja dan jika ada responden yang melanggar akan diingatkan oleh rekan yang lainnya. Responden mengetahui dan memahami dengan baik SOP dan instruksi yang ada di perusahaan. Responden memahami bagaimana cara bekerja yang baik dan aman. Peralatan kerja dan APD yang dibutuhkan juga telah disediakan oleh perusahaan. Responden juga mendapatkan dukungan yang baik dari supervisor mereka. Supervisor unit assembly senantiasa mengingatkan jika ada pekerja yang melanggar sebelum diketahui oleh tim HSE.

Model Precede-Proceed dari Green dalam Notoatmodjo (2010), menyebutkan bahwa perilaku dipengaruhi oleh 3 faktor yaitu predisposing, enabling, dan reinforcing. Faktor predisposing ialah faktor dari dalam diri subjek, yaitu pengetahuan, sikap, motivasi dsb. Dalam hal ini responden memiliki faktor predisposing yang positif yaitu pengetahuan yang cukup dan sikap yang baik terhadap SOP. Faktor enabling juga terpenuhi yaitu fasilitas yang dibutuhkan untuk bekerja sesuai dengan SOP, dan SOP itu sendiri yang tertulis yang dapat diakses oleh semua pekerja. Selain itu juga diadakan pelatihan kepada pekerja agar bekerja aman sesuai dengan SOP. Selain itu faktor reinforcing juga positif dengan adanya dukungan dari keluarga, rekan kerja, supervisor dan dari perusahaan. 
Sebagian besar responden fabrikasi unit painting yang kurang patuh terhadap SOP PT. Bangun Sarana Baja Gresik mengerti terhadap isi dan instruksi yang ada di SOP PT. Bangun Sarana Baja Gresik dan juga tentang SOP PT. Bangun Sarana Baja Gresik namun tidak memiliki sikap yang positif terhadap SOP. Sebagian besar responden yang kurang patuh merasa terbebani dengan adanya SOP. Mereka menganggap SOP adalah hal yang membuat pekerjaan mereka semakin sulit. Saat pekerjaan yang mereka lakukan berbeda dari SOP namun selama hasilnya tercapai mereka merasa tidak ada masalah. Pada unit painting responden yang kurang patuh beberapa tidak menggunakan APD dan saat menggunakan mesin painting ada yang tidak membersihkan sisasisa hasil painting. Supervisor unit painting jarang memberikan teguran terhadap responden yang melanggar. Supervisor hanya memberikan tugas dan kurang menekankan peran prosedur.

Dalam salah satu penelitian yang dilakukan oleh Natasia (2014), dia dapat hasil bahwa sikap atau persepsi terhadap SOP memiliki pengaruh yang signifikan terhadap kepatuhan seseorang terhadap prosedur yang ditetapkan. Dari penelitian tersebut didapat hasil pekerja yang memiliki persepsi yang baik terhadap SOP memiliki tingkat kepatuhan sebesar 1,984 kali lebih baik dibanding dengan yang memiliki persepsi yang buruk terhadap SOP dan juga sebaliknya. Pada responden unit painting tidak memiliki persepsi yang baik terhadap SOP dan menganggap SOP adalah hal yang mengganggu, bukan membantu. Jika dikaji dari model Green, pada faktor predisposing pengetahuan responden menunjukkan hasil positif, namun sikap menunjukkan hal negatif. Faktor enabling terpenuhi oleh perusahaan dengan menyediakan peralatan kerja dan APD yang sesuai terhadap pekerjaan. Tidak terpenuhinya faktor tersebut dalam teori Green menyebabkan perilaku tidak terjadi atau terhambat pembentukannya.

\section{Gaya Kepemimpinan}

Gaya kepemimpinan path goal yang cenderung ditunjukkan oleh supervisor unit drilling adalah sangat baik. Dalam hal ini dapat dikatakan supervisor unit drilling memiliki tingkat penguasaan yang maksimal dalam penerapan gaya kepemimpinan path goal pada pekerjaan sehari hari. Beberapa sikap yang dapat dilihat langsung oleh pekerja yaitu supervisor unit drilling memberi tahu pekerja aktivitas dan langkah kerja yang harus dilakukan, supervisor unit drilling berpesan pada pekerja untuk menyelesaikan pekerjaan dengan sangat baik, supervisor unit drilling membuat suasana bekerja yang nyaman untuk pekerja, supervisor unit drilling mau mendengarkan saran dari pekerja, supervisor unit drilling meminta pekerja untuk menaati peraturan yang berlaku di tempat kerja, supervisor unit drilling mau memberikan motivasi pada pekerja, dan supervisor unit drilling menjelaskan tentang pencapaian kerja dan supervisor unit drilling meminta pekerja menyelesaikan tugas tepat waktu. Supervisor unit drilling memiliki gaya kepemimpinan path goal yang sangat baik, artinya supervisor unit drilling mampu menyelesaikan pekerjaan dengan sangat baik dan mampu mengorganisasikan sumber daya manusia secara efektif dan efisien berdasarkan tujuan sehari hari dalam pekerjaannya.

Gaya kepemimpinan path goal yang cenderung ditunjukkan oleh supervisor unit marking cutting adalah baik. Dalam hal ini dapat dikatakan supervisor unit marking cutting memiliki tingkat penguasaan yang cukup baik dalam penerapan gaya kepemimpinan path goal pada pekerjaan sehari hari dalam pekerjaannya. Beberapa sikap yang dapat dilihat langsung oleh pekerja yaitu supervisor unit marking cutting memberi tahu pekerja aktivitas dan langkah kerja yang harus dilakukan, supervisor unit marking cutting berpesan pada pekerja untuk menyelesaikan pekerjaan dengan sangat baik, supervisor unit marking cutting membuat suasana bekerja yang nyaman untuk pekerja, supervisor unit marking cutting meminta pekerja untuk menaati peraturan yang berlaku di tempat kerja, supervisor unit marking cutting menjelaskan tentang pencapaian kerja dan supervisor unit marking cutting meminta pekerja menyelesaikan tugas tepat waktu. Supervisor unit marking cutting memiliki gaya kepemimpinan path goal yang baik, artinya supervisor unit marking cutting mampu menyelesaikan pekerjaan dengan baik dan mampu mengorganisasikan sumber daya manusia secara efektif dan efisien namun sebenarnya masih bisa ditingkatkan lebih baik lagi.

Gaya kepemimpinan path goal yang cenderung ditunjukkan oleh supervisor unit assembly adalah sangat baik. Dalam hal ini dapat dikatakan supervisor unit assembly memiliki tingkat penguasaan yang maksimal dalam penerapan gaya kepemimpinan path goal pada pekerjaan sehari hari. Beberapa sikap yang dapat dilihat langsung oleh pekerja yaitu supervisor unit assembly berpesan pada pekerja untuk menyelesaikan dengan sangat baik, supervisor unit assembly membuat suasana 
bekerja yang nyaman untuk pekerja, supervisor unit assembly mau mendengarkan saran dari pekerja, supervisor unit assembly meminta pekerja untuk menaati peraturan yang berlaku di tempat kerja, supervisor unit assembly mau memberikan motivasi pada pekerja, supervisor unit assembly suka memberi pujian pada pekerja, supervisor unit assembly menjelaskan tentang pencapaian kerja dan supervisor unit assembly meminta pekerja menyelesaikan tugas tepat waktu. Supervisor unit assembly memiliki gaya kepemimpinan path goal yang sangat baik, artinya supervisor unit assembly mampu menyelesaikan pekerjaan dengan sangat baik dan mampu mengorganisasikan sumber daya manusia secara efektif dan efisien berdasarkan tujuan sehari hari dalam pekerjaannya.

Gaya kepemimpinan path goal yang cenderung ditunjukkan oleh supervisor unit painting adalah kurang. Dalam hal ini dapat dikatakan supervisor unit painting memiliki tingkat penguasaan yang kurang dalam penerapan gaya kepemimpinan path goal pada pekerjaan sehari hari dalam pekerjaannya.

Beberapa sikap yang dapat dilihat langsung oleh pekerja yaitu supervisor unit painting memberi tahu pekerja aktivitas dan langkah kerja yang harus dilakukan, supervisor unit painting berpesan pada pekerja untuk menyelesaikan pekerjaan dengan sangat baik, supervisor unit painting menjelaskan tentang pencapaian kerja dan supervisor unit painting meminta pekerja menyelesaikan tugas tepat waktu. Supervisor unit painting memiliki gaya kepemimpinan path goal yang kurang, artinya supervisor unit painting mampu menyelesaikan pekerjaan namun masih kurang maksimal dalam mengorganisasikan sumber daya manusia secara efektif dan efisien dan sebenarnya masih bisa ditingkatkan lebih baik lagi.

\section{Hubungan Gaya Kepemimpinan dan Kepatuhan}

Secara umum supervisor bagian fabrikasi yang ada di Pabrik Baja Gresik memiliki gaya kepemimpinan yang berbeda antara satu sama lain. Menurut hasil penelitian, hal ini memiliki hubungan dengan tingkat kepatuhan pekerja masing-masing unit yang dipimpin oleh supervisor.

Kepemimpinan yang diterapkan oleh masingmasing supervisor pekerja fabrikasi di Pabrik Baja Gresik berbeda antara satu dengan yang lain. Hal ini membuktikan supervisor memiliki kemampuan yang berbeda beda dalam memimpin bawahannya.
Dari hasil penelitian distribusi Hubungan Antara Gaya Kepemimpinan Path Goal Supervisor dengan tingkat kepatuhan Penerapan SOP Pekerja Bagian Fabrikasi di Area Workshop Pabrik Baja Gresik Gresik, didapatkan hasil penelitian yang menunjukkan adanya hubungan gaya kepemimpinan tiap supervisor dengan tingkat kepatuhan masingmasing bawahannya.

Supervisor Unit Drilling memiliki gaya kepemimpinan path goal yang sangat baik dan sejumlah 2 responden kurang patuh (13,3\%) terhadap SOP dan sejumlah 13 responden $(86,6 \%)$ patuh terhadap SOP. Supervisor unit drilling menerapkan gaya kepemimpinan path goal sesuai dengan situasi kondisi yang membutuhkan. Supervisor unit drilling mampu untuk menggunakan keempat elemen yang ada secara bersamaan sesuai dengan tuntutan pekerjaan yang dibutuhkan untuk mencapai tujuan. Dalam pekerjaan sehari hari unit drilling dihadapkan oleh pekerjaan yang membutuhkan ketelitian yang tinggi. Supervisor unit drilling aktif dalam memberi edukasi terhadap para pekerja terkait SOP pada saat safety meeting. Supervisor unit drilling juga ketat dalam pemberlakuan sistem denda oleh perusahaan terhadap pekerja yang melanggar aturan khususnya aturan-aturan keselamatan. Hal ini menunjukkan Supervisor unit drilling mampu menerapkan elemen direktif, yaitu mampu memberi arahan atau langkahlangkah untuk mencapai tujuan kelompok.

Supervisor unit drilling jika menemui pekerja yang menemui hambatan dalam penerapan kepatuhan SOP, seperti halnya kurang mengetahui soal informasi SOP, cara pengerjaan tugas dan aturan keselamatan, Supervisor unit drilling unit drilling membantu memberikan solusi terhadap pekerja seperti memberi softcopy SOP yang ada dan membantu menemukan solusi dengan membahasnya di luar jam kerja seperti di warung atau pada saat istirahat. Hal ini menunjukkan Supervisor unit drilling menerapkan elemen suportif yang memiliki ciri pemimpin memberi dukungan moriil dalam pencapaian tujuan.

Dalam pekerjaan sehari hari supervisor unit drilling juga sama mengikuti aturan keselamatan yang ditentukan perusahaan dan bekerja bersama di tempat yang sama dengan pekerjanya. Hal ini menunjukkan Supervisor unit drilling menerapkan elemen partisipatif yang memiliki ciri pemimpin bersama-sama berpartisipasi untuk mencapai tujuan.

Untuk menjaga kualitas supervisor unit drilling selalu menekankan responden untuk mentaati 
SOP yang ditentukan, agar hasil drilling tidak melenceng dari gambar teknik yang dipesan. Hal ini menunjukkan supervisor unit drilling menerapkan elemen achievement oriented yang memiliki ciri pemimpin menetapkan tujuan kepada bawahan.

Hal diatas menurut responden menjadi salah satu alasan mereka mematuhi SOP yang ada di Pabrik Baja Gresik. Mematuhi SOP menurut responden menjadi hal yang tidak mudah karena butuh niat, penyesuaian, fasilitas dan dukungan yang cukup. Responden unit drilling yang patuh terhadap SOP merasa gaya kepemimpinan supervisor unit drilling membantu mereka untuk mengatasi hambatan kepatuhan SOP. Beberapa alasan yang dominan yaitu adanya dukungan dari supervisor, pemberian instruksi yang jelas dari supervisor, dan penegakan aturan yang ketat oleh supervisor terkait pelanggaran. Hal tersebut menjadi faktor pendorong bagi responden unit drilling untuk mematuhi SOP. Sementara bagi pekerja yang kurang patuh terhadap SOP mengaku kurang memahami SOP yang ditentukan dan kurangnya kedisiplinan.

Supervisor Unit Marking-Cutting memiliki gaya kepemimpinan path goal yang baik dan sejumlah 3 responden kurang patuh $(21,43 \%)$ terhadap SOP dan sejumlah 13 responden $(86,6 \%)$ patuh terhadap SOP. Supervisor unit marking-cutting menerapkan gaya kepemimpinan path goal sesuai dengan situasi kondisi yang membutuhkan namun masih kurang pada salah satu elemen. Supervisor unit marking-cutting mampu untuk menggunakan tiga elemen dengan baik yaitu direktif, partisipatif dan achievement oriented namun masih kurang dalam elemen suportif.

Dalam keseharian bekerja Supervisor unit marking-cutting memberi arahan bagaimana seharusnya pekerjaan dilakukan. Unit markingcutting adalah unit pertama proses fabrikasi jika baja tidak dilakukan sandblasting, sehingga unit lainnya baru akan bekerja jika unit marking cutting sudah menyelesaikan pekerjaannya. Oleh karena itu unit marking cutting harus dengan cepat dan tepat dalam menyelesaikan pekerjaannya. Menjadi yang pertama dalam proses pengerjaan fabrikasi, unit marking cutting harus benar-benar rapi dalam pengerjaan sehingga tidak mengacaukan prosesproses berikutnya seperti drilling, assembly dan painting.

Supervisor unit marking-cutting memberi arahan yang jelas agar pekerja memahami pekerjaan yang dilakukan, agar tuntutan target bisa terpenuhi sesuai waktu, kualitas dan memperlancar proses berikutnya dalam pengerjaan fabrikasi. Supervisor unit marking-cutting dalam instruksinya selalu jelas bagi pekerja, khususnya terkait kepatuhan terhadap SOP. Salah satu contoh adalah supervisor unit marking-cutting memberi tahu dan menegur jika ada pekerja yang hanya memberi gambar pada plat baja tidak menggunakan APD atau pekerja yang merokok sambil bekerja. Hal ini menunjukkan supervisor unit marking-cutting menerapkan elemen direktif yang memiliki ciri pemimpin menunjukkan kepada bawahan cara untuk meraih tujuan. Dalam hal ini supervisor unit marking-cutting memberikan instruksi bagaimana untuk melakukan pekerjaan yang baik dengan mematuhi SOP untuk mencapai kualitas pekerjaan dan keselamatan kerja.

Dalam pekerjaan sehari hari supervisor unit drilling juga sama mengikuti aturan keselamatan yang ditentukan perusahaan dan bekerja bersama di tempat yang sama dengan pekerjanya. Hal ini menunjukkan Supervisor unit marking-cutting menerapkan elemen partisipatif yang memiliki ciri pemimpin bersama-sama berpartisipasi untuk mencapai tujuan.

Dalam pekerjaan sehari hari unit markingcutting dihadapkan oleh pekerjaan yang membutuhkan ketelitian yang tinggi karena harus memberi tanda pada baja yang akan dipotong. Hasil potongan akan menentukan kualitas dan fungsi dari baja yang dipesan. Oleh karena itu jika baja yang dipotong tidak rapi dan bagus pengerjaannya akan mengecewakan pelanggan dan akan mempersulit pekerjaan unit assembly. Supervisor unit markingcutting aktif dalam memberi pemahaman terhadap para pekerja terkait kualitas pengerjaan yang didapat melalui kepatuhan SOP pada saat safety meeting. Karena secara tidak langsung jika pekerja mematuhi SOP yang ada, pekerjaan akan menghasilkan kualitas yang baik dan seragam juga aman bagi pekerja.

Responden unit marking-cutting merasa terbantu dalam memenuhi SOP yang ditetapkan oleh perusahaan karena gaya kepemimpinan yang diterapkan oleh Supervisor unit marking-cutting. Selain adanya fasilitas yang mendukung, Supervisor unit marking-cutting juga memberikan pemahaman yang baik kepada responden tentang SOP. Seringkali supervisor unit marking-cutting mengingatkan jika aturan yang dibuat oleh perusahaan tidak hanya bertujuan untuk menguntungkan perusahaan saja namun juga demi keselamatan dan kesehatan pekerja saat bekerja.

Responden unit marking-cutting yang patuh terhadap SOP merasa gaya kepemimpinan 
supervisor unit marking-cutting membantu mereka untuk memahami fungsi SOP untuk pekerja. Hal ini dapat dilihat dari sikap dan tindakan responden terhadap SOP memiliki nilai yang baik. Beberapa alasan yang dominan yaitu adanya pemahaman dari supervisor dan pemberian instruksi yang jelas dari supervisor. Hal tersebut menjadi faktor pendorong bagi responden unit marking-cutting untuk mematuhi SOP. Sementara bagi pekerja yang kurang patuh terhadap SOP mengaku kurang mendapatkan dukungan saat mengalami hambatan dalam berusaha mematuhi SOP yang ada. Saat pekerja berusaha memberi masukan terkait kesulitan pekerjaan supervisor kurang bisa mendengarkan saran dari pekerja.

Supervisor Unit assembly memiliki gaya kepemimpinan path goal yang sangat baik dan seluruh responden patuh terhadap SOP. Supervisor unit assembly menerapkan gaya kepemimpinan path goal sesuai dengan situasi dan kondisi yang membutuhkan. Supervisor unit assembly mampu untuk menggunakan keempat elemen yang ada secara bersamaan sesuai dengan tuntutan pekerjaan yang dibutuhkan untuk mencapai tujuan. Unit assembly adalah unit yang membutuhkan ketelitian dan perhatian, karena kualitas pemasangan baja sangat berkaitan dengan kekuatan, tingkat keamanan dan keselamatan baja tersebut saat digunakan. Oleh karena itu supervisor menekankan kepada pekerja untuk harus selalu patuh terhadap SOP yang ditentukan perusahaan.

Supervisor unit assembly aktif dalam memberi penerangan terhadap para pekerja terkait SOP pada saat safety meeting. Supervisor unit assembly juga ketat dalam pemberlakuan sistem denda oleh perusahaan terhadap pekerja yang melanggar aturan khususnya aturan-aturan keselamatan. Hal ini menunjukkan Supervisor unit assembly mampu menerapkan elemen direktif, yaitu mampu memberi arahan atau langkah-langkah untuk mencapai tujuan kelompok.

Supervisor unit assembly mau mendengarkan saran dan masukan dari pekerja khususnya terkait permasalahan SOP yang menyangkut keselamatan dan kesehatan kerja responden. Sebagai salah satu contoh saat ada pekerja yang merokok di warehouse, Supervisor unit assembly oleh salah satu responden mau diajak untuk berdiskusi memberi sistem hukuman selain denda uang yang ditetapkan perusahaan agar tidak terulang. Jika menemui pekerja yang menemui hambatan dalam penerapan kepatuhan SOP, seperti halnya kurang mengetahui soal informasi SOP, cara pengerjaan tugas dan aturan keselamatan, Supervisor unit assembly unit drilling membantu memberikan solusi terhadap pekerja seperti memberi softcopy SOP yang ada. Hal ini menunjukkan Supervisor unit assembly menerapkan elemen suportif yang memiliki ciri pemimpin memberi dukungan moriil dalam pencapaian tujuan.

Dalam pekerjaan sehari hari supervisor unit drilling juga sama mengikuti aturan keselamatan yang ditentukan perusahaan dan bekerja bersama di tempat yang sama dengan pekerjanya. Hal ini menunjukkan Supervisor unit assembly menerapkan elemen partisipatif yang memiliki ciri pemimpin bersama-sama berpartisipasi untuk mencapai tujuan.

Untuk menjaga kualitas supervisor unit assembly selalu menekankan responden untuk mentaati SOP yang ditentukan, agar hasil pemasangan baja pas dan kuat untuk digunakan. Hal ini menunjukkan supervisor unit assembly menerapkan elemen achievement oriented yang memiliki ciri pemimpin menetapkan tujuan kepada bawahan.

Gaya kepemimpinan yang diterapkan oleh Supervisor unit assembly bagi responden sangatlah membantu dalam pencapaian kepatuhan SOP. Bagi responden unit assembly, Supervisor unit assembly ialah supervisor yang mau mendengarkan pekerjanya dan tegas dalam waktu yang sama. Keempat elemen path goal tersebut dirasakan oleh responden saat Supervisor unit assembly bekerja sehari hari.

Bagi responden unit assembly beberapa alasan yang dominan yang menjadi faktor pendorong ialah adanya dukungan dari supervisor, pemberian instruksi yang jelas dari supervisor, keterbukaan supervisor dan penegakan aturan yang ketat oleh supervisor terkait pelanggaran. Hal tersebut menjadi faktor pendorong bagi responden unit assembly untuk mematuhi SOP.

Supervisor Unit Painting memiliki gaya kepemimpinan path goal yang baik dan sejumlah 7 responden kurang patuh $(58,33 \%)$ terhadap SOP dan sejumlah 5 responden $(41,67 \%)$ patuh terhadap SOP. Supervisor unit painting dalam menerapkan gaya kepemimpinan path goal masih kurang. Dari hasil penelitian supervisor unit painting mampu untuk menggunakan dua elemen dengan baik yaitu partisipatif dan achievement oriented namun masih kurang dalam elemen direktif dan suportif.

Unit painting adalah unit terakhir dalam urutan proses fabrikasi baja. Setelah dipasang di unit assembly, baja diberikan kepada unit 
painting untuk dicat. Pengecatan adalah proses yang memerlukan kehati-hatian karena cat selain berfungsi memperindah juga memiliki fungsi untuk melindungi baja. Baja yang tidak tercat dengan baik akan mudah mengalami pengkaratan dan akan terlihat kurang indah.

Dalam pekerjaan sehari hari supervisor unit painting juga sama mengikuti aturan keselamatan yang ditentukan perusahaan dan bekerja bersama di tempat yang sama dengan pekerjanya. Hal ini menunjukkan Supervisor unit painting menerapkan elemen partisipatif yang memiliki ciri pemimpin bersama-sama berpartisipasi untuk mencapai tujuan.

Supervisor unit painting berusaha untuk menetapkan tujuan kepatuhan SOP dengan cara memberitahu pekerja bahwa SOP adalah hal yang penting. Penetapan tujuan oleh supervisor unit painting berdasarkan tugas unit painting yang memerlukan ketelitian dalam melakukan pekerjaan, agar tidak merugikan pekerjaan dan keselamatan pekerja sendiri.

Responden unit painting yang patuh terhadap SOP merasa gaya kepemimpinan supervisor unit painting membantu mereka untuk memahami fungsi SOP untuk pekerja walaupun belum maksimal. Responden unit painting yang patuh terhadap SOP mengaku patuh karena sudah memiliki sikap yang baik sejak awal, dan takut terkena denda jika ketahuan oleh staf HSE. Supervisor tidak melaporkan pekerjanya yang melanggar sehingga peraturan di unit painting relatif kurang ketat dibandingkan dengan unit lainnya. Responden yang patuh merasa kurang diberi tekanan dan arahan untuk mematuhi SOP yang ada.

Sementara bagi pekerja yang kurang patuh terhadap SOP mengaku kurang mendapatkan dukungan saat mengalami hambatan dalam berusaha mematuhi SOP yang ada dan juga supervisor tidak melaporkan bawahannya yang melanggar SOP. Tidak ada pemberian pemahaman atau arahan tentang manfaat maupun dampak kepatuhan SOP terhadap kesehatan dan keselamatan pekerja.

Hasil analisis statistik menunjukkan bahwa ada hubungan yang positif antara gaya kepemimpinan path goal supervisor dengan kepatuhan SOP bawahan dengan koefisien korelasi sebesar 0,441. Artinya, jika variabel gaya kepemimpinan naik maka begitu juga tingkat kepatuhan dan atau sebaliknya. Gaya kepemimpinan memiliki hubungan dengan tingkat kepatuhan SOP. Hal ini sejalan dengan penelitian yang dilakukan oleh

Penelitian yang dilakukan oleh Malik SH dkk (2014), menyebutkan bahwa gaya kepemimpinan merupakan suatu bentuk sifat dan perilaku atasan yang dilakukan seorang atasan terhadap subjek yang dipimpin. Subjek yang dipimpin dapat memberi respons negatif atau positif tergantung situasi dan kondisi yang sedang berlaku pada saat di mana gaya kepemimpinan itu efektif berlangsung. Dalam hal ini gaya kepemimpinan path goal yang positif memiliki dampak yang positif terhadap kepatuhan SOP bawahan. Jika gaya kepemimpinan yang diterapkan oleh supervisor sangat baik maka pekerja akan mematuhi SOP yang ada, begitu pula jika gaya kepemimpinan path goal diabaikan oleh pekerja maka pekerja akan cenderung mengabaikan SOP yang telah ditentukan perusahaan.

\section{SIMPULAN}

Setelah dilakukan penelitian, masing-masing supervisor menunjukkan gaya kepemimpinan yang berbeda beda satu sama lain dan memiliki hubungan dengan tingkat kepatuhan masing-masing responden di dalam unit tersebut

Berdasarkan hasil penelitian menunjukkan adanya hubungan positif antara gaya kepemimpinan path goal theory supervisor dengan tingkat kepatuhan pelaksanaan standard operating procedure pekerja bagian fabrikasi di area workshop Pabrik Baja Gresik. Hal ini menunjukkan bahwa semakin baik penguasaan gaya kepemimpinan path goal oleh supervisor akan memberikan dampak positif terhadap tingkat kepatuhan SOP dari bawahannya.

\section{DAFTAR PUSTAKA}

Depnakertrans. 2014. Angka Kcelakaan Kerja di Indonesia. Diunduh di Website Depnakertrans. $\mathrm{http}: / /$ pusdatinaker.balitfo.depnakertrans.go.id/

Dyan, Mochamad. 2013. Hubungan Gaya Kepemimpinan Situasional Supervisor dengan Tingkat Stress Kerja.Skripsi. Universitas Airlangga.

Eisenberger, R., Rhoades, L., Armeli, S. 2001. Affective Commitment to the Organization: The Contributiom of Perceived Organizational Support. Journal of Applied Psychology. 86 (4): 830-832. 
Feldman, Robert. 2011. Understanding Psychology. New York: McGraw-Hill.

Health and Safety Executives (HSE). 2014. Occupational Health and Safety Annual Report in Great Britain. (Sitasi 15 Oktober 2014).

House, R.J. 1996. Path-goal theory of leadership: Lessons, legacy, and a reformulated theory. Leadership Quarterly. 7 (3): 323-352.

Malik, S.H., Aziz S., Hassan H. 2014. Leadership Behaviour and Acceptance of Leader and Subordinates: Application of Path Goal Theory in Telecom Sector. International Journal of Trade, Economics and Finance, 5 (6), 173-174.

Natasia N, Loekqijana A, Kurniawati J. 2014. Faktor yang Mempengaruhi Kepatuhan Pelaksanaan SOP Asuhan Keperawatan di ICU-ICCU RSUD Gambiran Kota Kediri. Jurnal Kedokteran Brawijaya, 28 (4), 23-24.

Northouse, P. 2013. Leadership Theory and Practice. Thousand Oaks: Sage Publications, Inc.

Notoatmodjo, Soekidjo. 2007. Kesehatan Masyarakat, Ilmu dan Seni. Jakarta: Rineka Cipta.
Notoatmodjo, Soekidjo. 2010. Ilmu Perilaku Kesehatan. Jakarta: Rineka Cipta.

Pudjiono. 2003. Pengaruh kepemimpinan Transformasional dan Transaksional terhadap Komitmen Organisasi pada Perpustakaan Perguruan Tinggi Negeri di Kota Surabaya. Thesis. Universitas Airlangga.

Ridho, W.F. 2015. Hubungan Antara Gaya Kepemimpinan Metode Path Goal Theory Supervisor dengan Tingkat Kepatuhan Penerapan Standard Operating Procedure (SOP) (Studi Pada Pekerja Bagian Fabrikasi di Area Workshop PT. Bangun Sarana Baja Gresik). Skripsi. Universitas Airlangga.

Ridley, M. 2003. Nature Via Nurture. New York: Harper Collins.

Wade, C., Travis, C. 2007. Psikologi. Jakarta: Erlangga.

Zaini, M Agus. 2013. Hubungan Gaya Kepemimpinan Serta Penerapan Reward dan Punishment Terhadap Kepatuhan Pekerja dalam Melaksanakan Program K3 (Studi pada PT. Liku Telaga Gresik). Skripsi. Universitas Airlangga. 